\section{In this issue - October 2019}

\author{
Serge Savary ${ }^{1}$
}

Published online: 4 September 2019

(C) International Society for Plant Pathology and Springer Nature B.V. 2019

The October Issue of Food Security includes 12 articles, 10 original papers and two book reviews.

The first article by Souissi et al. ("Impact of food consumption on water footprint and food security in Tunisia") provides a rare and well documented analysis of the water footprint associated with local food production in a North African country, a region of the world confronted with climate change, water scarcity, and very fast population growth. The study puts valuable numbers on an oft-mentioned, yet rarely assessed, critical problem.

The second article, by B.F.Y. Khader et al. ("Where in the value chain are we losing the most food? The case of wheat in Jordan"), produces an analysis of the life cycle of food in Jordan. The study emphasises on losses and waste, in a country where resources, including natural resources, are scarce.

The third article, by W. Marivoet et al. ("How well does the Food Consumption Score capture diet quantity, quality and adequacy across regions in the Democratic Republic of the Congo (DRC)?"), is an important analysis of the Food Consumption Score in the Democratic Republic of the Congo. The study is based on a very large survey across a very large African country. The work demonstrates the potential use of household survey data to conduct this sort of food security validation exercises, especially for the World Food Programme.

The fourth paper, by P.M. Ntakyo and M. van den Berg ("Effect of market production on rural household food consumption: evidence from Uganda") addresses the possible competition between for-sale and household-intended food production. The study suggests (and discusses) that, in this particular case, the competition indeed exists, with a reduction in caloric intake.

Serge Savary

serge.savary@inra.fr

1 Institut National de la Recherche Agronomique, INRA, Auzeville, France
The fifth article, by Taiyang Zhong et al. ("Achieving urban food security through a hybrid public-private food provisioning system: the case of Nanjing, China") addresses food security in cities of the Global South. Based on of household survey data, interviews and government documents, the study reveals that both Nanjing's food provisioning system and its governance operate in a public-private hybrid model. The authors discuss the structure of the model and its policy implications.

The sixth article, by Jiaojiao Li et al. ("Food access inequalities in Chinese urban neighborhoods: a case study of the Dalian development zone") provides a detailed analysis of food access in a Chinese city, where the access-transit-time to different category of foods is analysed for residents living in thousands of buildings using a GIS interface. Access to food appears associated to household wealth.

In the seventh article, by A. Shee et al. ("Determinants of postharvest losses along smallholder producers' maize and Sweetpotato value chains: an ordered Probit analysis"), postharvest loss at the multiple successive stage of post-harvest processes are quantified. This analysis, on maize and sweetpotato by smallholders in sub-Saharan Africa appears to be the first of its kind, enabling the identification of entry points for improvements and reduction of post-harvest losses.

The eighth article, by S. Nordhagen et al. ("The sustainability of a nutrition-sensitive agriculture intervention: a case study from urban Senegal"), examines the sustainability of a nutrition-sensitive agriculture project implemented in Dakar. The study indicates that nutrition knowledge remained at project level. The sustainability of nutrition-sensitive agriculture appears to depend on project-provided incentives, the improvement of incomes (rather than production, in urban environments), and the re-enforcing over time of nutrition knowledge among parents of young children.

The ninth article, by M. Izraelov and J. Silber ("An assessment of the global food security index") is an analysis of the measures of food insecurity, at the household or at the national level. Some of these measures emphasise the determinants of food security, or the consequences of food insecurity. The 
analysis focuses on the Global Food Security Index (GFSI), and concludes that both the weights selected and the indicators used in the GFSI reasonably rank a large number of countries in the world, with respect to food security.

The tenth article, by D. Natalini et al. ("Global food security and food riots - an agent-based modelling approach"), addresses the increasing instability of food security, resulting in riots, using an agent-base model, where each agent is one of 213 countries in the world. The article provides details on the development, calibration, and evaluation of the model. The authors then offer forecasts in terms of food prices and possible riots.

The October issue concludes with two book reviews. One reports on the book "Agriculture, Development and the Global Trading System (2000-2015)", edited by A. Bouet and D. Laborde, and second, on the book "The transformation of Rural Africa", edited by T.S. Jayne, J. Chamberlin, and R. Benfica. 